\title{
TEORI DAN PRAKTEK WAKAF
}

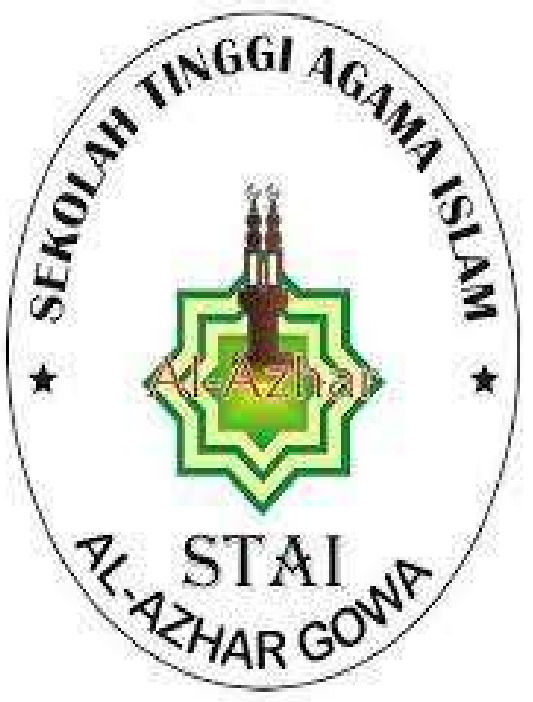

Makalah Diajukan untuk memenuhi tugas mata kuliah fikih zakat dan wakaf

Oleh :

Enny Winarni

Nafisah Kuri'ain

Dosen :

Samsul Arifai, S.A.B., M.A.

\section{EKONOMI SYARIAH STAI AL-AZHAR GOWA \\ 2021}




\section{DAFTAR ISI}

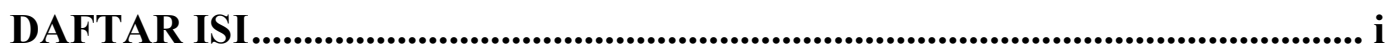

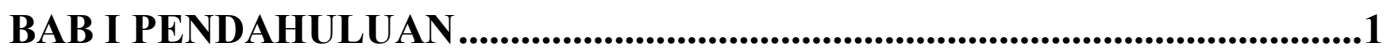

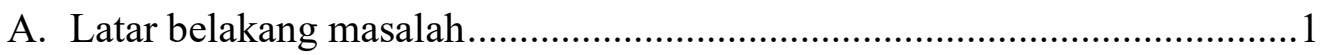

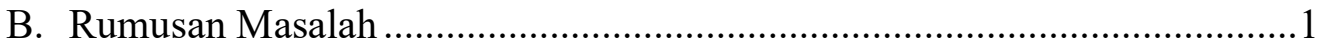

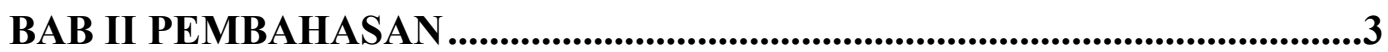

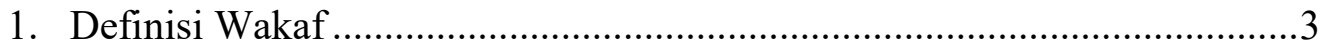

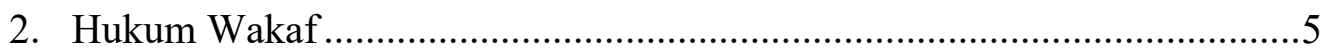

3. Rukun dan Syarat Wakaf .........................................................................

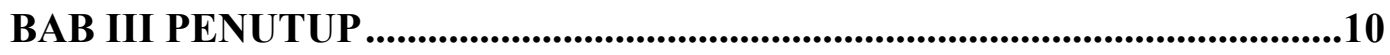

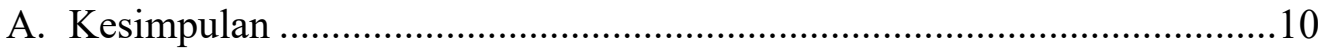

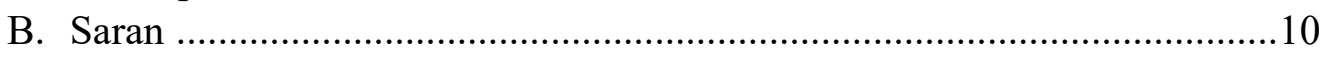

DAFTAR PUSTAKA ...............................................................................................12 


\section{BAB I \\ PENDAHULUAN}

A. Latar Belakang

Term-term sosial dalam khazanah kajian fiqh muamalat, diantaranya adalah rahn, kafalah, wakalah, hiwalah, ju'alah dan sharf. Selain itu, ada beberapa instrumen lain yang tak kalah pentingnya, yaitu zakat, infak, sedeqah dan wakaf. Dalam makalah singkat ini pemakalah cenderung untuk mengangkat persoalan wakaf, dengan alasan bahwa kajian dan aplikasi wakaf tidak akan pernah redup dibahas mengingat fungsinya yang sangat urgen dan memiliki potensi yang sangat besar dalam menyelesaikan persoalan-persoalan keumatan. Bahasan wakaf banyak dapat kita jumpai dalam litelatur kajian Islam. Berderet kitab, baik dalam bentuk menuskrip maupun kitab yang terekam dalam bentuk tulisan modern telah tersaji, sehingga kita sebagai penikmat dengan leluasa dapat mengkonsumsinya. Dapat dipahami demikian, karena pengkajian terhadap posisi wakaf sendiri memiliki nilai dan kegunaan yang begitu urgen dalam proses dakwah dan kesejahteraan umat. Pembahasan wakaf telah mengalami perkembangan sejalan dengan tuntutan perubahan zaman. Dimulai dari kajian wakaf klasik hingga inovasi-inovasi mutakhir berkenaan dengan pengembangan wakaf. Pada abad-abad terakhir, naluri kajian wakaf mengarah kepada wakaf yang lebih mensejahterakan ganda. Artinya, selain nilai positif dari wujud benda wakaf itu sendiri, juga dituntut adanya produktifitas lain yang dapat dirasakan dan berkorelasi positif dengan misi dakwah demi kesejahteraan umat dari sisi ekonomi. Lebih kongkrit, wakaf mengarah kepada uang yang lebih nyata produktifitasnya, karena ia mampu menjadi instrument investasi yang efektif. Di indonesia telah mengenal wakaf baik setelah Islam masuk maupun sebelum Islam masuk, umumnya wakaf yang dikenal pada masa sebelum Islam masuk atau oleh agama-agama lain diluar Islam hampir sama dengan Islam yaitu untuk peribadatan. Dengan kata lain, lembaga wakaf telah dikenal oleh masyarakat pada peradaban yang cukup jauh dari masa sekarang. Namun, tujuan utama dari wakafnya yang berbeda-beda(untuk mendapat pahala, hanya untuk masyarakat umum,dll). Sedangkan setelah masuknya Islam istilah wakaf mulai dikenal. Sehingga ketika wakaf dikenal di Indonesia juga mempengaruhi pengaturan perwakafan tanah yang peruntukannya sebagai tempat-tempat peribadatan dan sosial yang dibuatnya peraturanperaturan yang lebih khusus mengenai wakaf diera setelah kemerdekaan.

B. Rumusan masalah

a. Apa definisi wakaf? 
b. Apa saja hukum yang mendasari adanya wakaf?

c. Bagaimana syarat dan rukun dalam wakaf? 


\section{BAB II PEMBAHASAN}

1. Definisi wakaf

Dalam bahasa Arab terdapat tiga kata-kata yang mempunyai makna yang sama, yaitu, dan Semuanya ber arti menahan. Rasulullah Muhammad Saw menggunakan kata-kata dan dalam hadisnya tentang wakaf. ${ }^{1}$

Pengertian wakaf di atas mengemukakan beberapa ciri khas wakaf, yaitu: (1) Penahanan (pencegahan) dari menjadi milik dan obyek yang dimilikkan. Penahanan berarti ada yang menahan yaitu Wakif dan tujuannya yaitu mauquf 'alaihi (penerima wakaf). (2) Harta, menjelaskan bahwa yang diwakafkan adalah harta. (3) Yang mungkin dimanfaatkan, tanpa lenyap bendanya, menjelaskan syarat harta yang diwakafkan. (4) Dengan cara tidak melakukan tindakan pada bendanya, menjelaskan bahwa harta wakaf tidak dijual, dihibahkan dan diwariskan. (5) Disalurkan kepada yang mubah dan ada, menjelaskan bahwa hasil wakaf itu disalurkan kepada yang tidak dilarang oleh Islam. Sedangkan, menyalurkannya kepada yang haram adalah haram. Dalam makna yang sama, para fuqaha memahaminya bahwa wakaf: 3 Menahan Asalnya dan menyalurkan manfaatnya. Dari dua defenisi di atas, para fuqaha silang pendapat tentang kepemilikan barang yang telah diwakafkan tersebut, apakah mauquf tersebut tetap milik wakif, atau berpindah tangan kepada mauquf alaih, atau justru menjadi milik Allah Swt. Ulama Syafi'iyah dan pengikut dari Abu Hanifah berpendapat bahwa harta wakaf tersebut menjadi milik Allah Swt. Imam Abu Hanifah dan madzhab Malikiyah, harta wakaf adalah tetap milik wakif. Sedangkan, madzhab Hanbali, harta wakaf milik mauquf alaih.

Secara bahasa, wakaf berasal dari kata waqf yang berarti radiah (terkembalikan), al-tahbis (tertahan), al-tasbil (tertawan), dan al-man'u (mencegah). Secara istilah, para ulama mendefinisikan wakaf sebagai berikut: ${ }^{2}$

1. Muhammad al-Syarbini al-Khatib berpendapat bahwa wakaf ialah penahanan harta yang memungkinkan untuk dimanfaatkan disertai dengan kekalnya zat benda dengan memutuskan (memotong) tasharruf (pertolongan) dalam penjagaannya atas mushrif (pengelola) yang dibolehkan adanya.

\footnotetext{
${ }^{1}$ Muhammad Fudhail Rahman, "Wakaf Dalam Islam," Al-lqtishad: Jurnal Ilmu Ekonomi Syariah 1, no. 1 (2009), https://doi.org/10.15408/aiq.v1i1.2455.

${ }^{2}$ H. Aden Rosadi, Zakat dan Wakaf Konsepsi, Regulasi, dan Implementasi, vol. 53, 2019.
} 
2. Ahmad Azhar Basyir berpendapat bahwa yang dimaksud dengan wakaf ialah menahan harta yang dapat diambil manfaatnya yang tidak musnah seketika, dan untuk penggunaan yang dibolehkan serta dimaksudkan untuk mendapat rida Allah.

3. Idris Ahmad berpendapat, wakaf ialah menahan harta yang mungkin dapat diambil manfaatnya, kekal zatnya, dan menyerahkannya ke tempat-tempat yang telah ditentukan syara' serta dilarang leluasa pada benda-benda yang dimanfaatkannya itu.

Dapat disimpulkan bahwa definisi zakat merupakan penahanan suatu zat yang kekal yang digunakan untuk kemaslahatan dan ditujukan untuk kebaikan orang banyak, dengan cara memberikan harta dengan maksud dan tujuan untuk mendekatkan diri kepada Allah dan menambah pahala bagi orang yang melakukan wakaf.

Sedangkan pengertian wakaf menurut Undang-undang adalah sebagai berikut. $^{3}$

1. Kompilasi Hukum Islam Pasal 215 ayat 1 Wakaf adalah perbuatan hukum seseorang atau kelompok orang atau badan hukum yang memisahkan sebagian dari benda miliknya dan melembagakannya untuk selama-lamanya guna kepentingan ibadah atau keperluan umum lainnya sesuai dengan ajaran Islam. Berdasarkan ketentuan Pasal 215 ayat 4 KHI tentang pengertian benda wakaf adalah : Segala benda baik bergerak atau tidak bergerak yang memiliki daya tahan yang tidak hanya sekali pakai dan bernilai menurut ajaran Islam.

2. Menurut UU No. 41 Tahun 2004 Tentang Wakaf Pasal 1 ayat (1) dan PP No. 42 Tahun 2006 Tentang Pelaksanaan UU No. 41 Tahun 2004 tentang wakaf Pasal 1 ayat (1) menyatakan bahwa Wakaf adalah perbuatan hukum wakif untuk memisahkan dan/atau menyerahkan sebagian harta benda miliknya untuk dimanfaatkan selamanya atau untuk jangka waktutertentu sesuai dengan kepentingannya guna keperluan ibadah dan/atau kesejahteraan umum menurut syarieeah.

Dari beberapa definisi wakaf tersebut, dapat disimpulkan bahwa wakaf bertujuan untuk memberikan manfaat atau faedah harta yang diwakafkan kepada orang yang berhak dan dipergunakan sesuai dengan ajaran syariah Islam. Hal ini sesuai dengan fungsi wakaf yang disebutkan pasal 5 UU No. 41 tahun 2004 yang menyatakan bahwa wakaf berfungsi

\footnotetext{
${ }^{3}$ Sinta Indi Astuti, Septo Pawelas Arso, dan Putri Asmita Wigati, “済無No Title No Title No Title," Analisis Standar Pelayanan Minimal Pada Instalasi Rawat Jalan di RSUD Kota Semarang 3 (2015): 103-11.
} 
mewujudkan potensi dan manfaat ekonomis harta benda wakaf untuk kepentingan ibadah dan untuk memajukan kesejahteraan umum.

2. Hukum Wakaf

Salah satu hukum yang mendasari adanya wakaf adalah terdapat di dalam Al-Quran. Dalam Al-Qurean, kata wakaf sendiri tidak secara eksplisit disebutkan, akan tetapi keberadaannya diilhami oleh ayat-ayat Al-Qur an dan contoh dari Rasulullah saw serta tradisi para sahabat. Dasar hukum wakaf tersebut adalah sebagai berikut:

1) Al-Qurean Beberapa ayat yang telah mengilhami dan dapat digunakan sebagai pedoman atau dasar seseorang untuk melakukan ibadah wakaf, dan menjadikannya sebagai sarana untuk mendekatkan diri kepada-Nya. Ayat-ayat tersebut antara lain sebagai berikut.

a. Quran surah Ali-Imran ayat 92

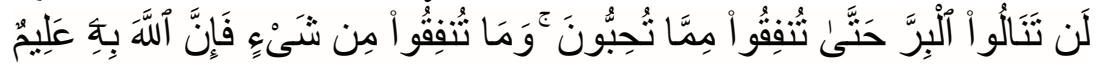

Artinya: Kamu sekali-kali tidak sampai kepada kebajikan (yang sempurna), sebelum kamu menafkahkan sebahagian harta yang kamu cintai. dan apa saja yang kamu nafkahkan Maka Sesungguhnya Allah mengetahuinya. ${ }^{4}$

b. Quran surah Yasin ayat 12

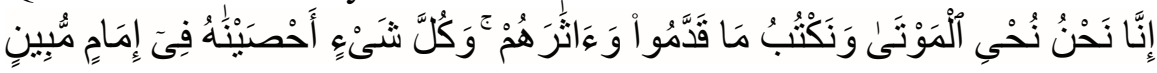

Arti: Sungguh, kamilah yang menghidupkan orang-orang yang mati, dan kamilah yang mencatat apa yang telah mereka kerjakan dan bekas-bekas yang mereka (tinggalkan). Dan segala sesuatu kami kumpulkan dalam kitab yang jelas (lauhulmahfudz). ${ }^{5}$

Dari ayat diatas, Syaikh Prof. Dr Khalid bin Ali Al-Musyaiqih berkata, "Diantara bekas yang ditinggalkan oleh orang yang telah wafat adalah wakaf." Sehingga secara umum wakaf juga termasuk dalam bentuk tolong-menolong dalam kebaikan dan ketakwaan. Dalam ayat-ayat di atas menjelaskan bahwa Allah memerintahkan kita untuk menafkahkan sebagian dari harta yang kita cintai, dan Allah pasti akan membalas semua yang kita lakukan dengan berlipatlipat. Maka nafkahkanlah sebagian dari rezki yang kita miliki dari

\footnotetext{
${ }^{4}$ Astuti, Arso, dan Wigati.

${ }^{5}$ DETIK.COM, "Seputar Wakaf: Pengertian, Hukum, Rukun, dan Syaratnya," 3 FEBRUARY 2021, n.d., https://www.kai.or.id/berita/18587/seputar-wakaf-pengertian-hukum-rukun-dansyaratnya.html.
} 
baik-baik agar kita mendapat kemenangan, karena Allah Maha luas lagi Maha Mengetahui.

2). Adapun hadist yang mendasari adanya wakaf adalah sebagai berikut. ${ }^{6}$

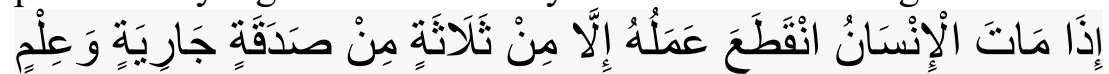

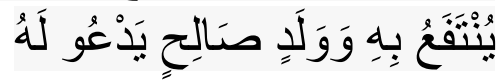

Artinya: "Jika seseorang meninggal dunia, maka terputuslah amalannya kecuali tiga perkara (yaitu): sedekah jariyah, ilmu yang dimanfaatkan, atau doa anak yang shalih." HR. MUSLIM

Yang dimaksud sedekah jariyah adalah amalan yang terus berlanjut manfaatnya. Seperti wakaf aktiva tetap contohnya, tanah, kitab, dan musnaf Al-Quran. Inilah alasan mengapa Ibnu Hajar Al-Asqalani memasukkan hadist ini dalam bahasa wakaf dalam Bulughul Maram. Karena para ulama menafsirkan sedekah jariah dengan wakaf.

3. Syarat dan Rukun wakaf

Wakaf akan dinyatakan sah apabila telah terpenuhi rukun dan syaratnya. Adapun rukun wakaf terdiri dari 4 macam dan syaratnya ada pada setiap rukun-rukun tersebut.

Adapun rukun wakaf adalah sebagai berikut.

1. Wakif adalah orang yang mewakafkan

2. Mauquf adalah barang yang diwakafkan

3. Mauquf 'alaih adalah orang atau lembaga yang berhak menerima harta wakaf

4. Shigat adalah pertanyaan wakif sebagai suatu kehendak untuk mewakafkan harta bendanya. ${ }^{7}$

Adapun syarat-syarat wakaf tersebut adalah sebagai berikut :

a. Waqif (orang yang mewakafkan). Dalam hal ini syarat waqif adalah merdeka, berakal sehat, baligh (dewasa), tidak berada di bawah pengampuan. Karena waqif adalah pemilik sempurna harta yang diwakafkan, maka wakaf hanya bisa dilakukan jika tanahnya adalah milik sempurna waqif tersebut.

6 محمد ابن زكرياى رازى, "Buku Pintar Wakaf," 1384.

7 Bagas SCRIBD, "Rukun Dan Syarat Wakaf," 23 september 2016, n.d., https://id.scribd.com/document/325004111/Rukun-Dan-Syarat-Wakaf. 
b. Mauquf bih (barang atau harta yang diwakafkan). Dalam perwakafan, agar dianggap sah maka harus memenuhi beberapa syarat sebagai berikut:

1. Harta wakaf itu memiliki nilai (ada harganya). Maksudnya adalah dalam praktiknya harta tersebut dapat bernilai apabila telah dimiliki oleh seseorang, dan dapat dimanfaatkan dalam kondisi bagaimanapun .

2. Harta wakaf itu jelas bentuknya. Artinya diketahui dengan yakin ketika benda tersebut diwakafkan, sehingga tidak akan menimbulkan persengketaan.

3. Harta wakaf itu merupakan hak milik dari waqif.

4. Harta wakaf itu berupa benda yang tidak bergerak, seperti tanah, atau benda yang disesuaikan dengan wakaf yang ada.

c. Maukuf 'alaih (peruntukan wakaf). Wakaf harus dimanfaatkan dalam batas-batas yang diperbolehkan oleh Syariat Islam, karena pada dasarnya wakaf merupakan amal yang bertujuan mendekatkan manusia pada Tuhan. Untuk menghindari penyalahgunaan wakaf, maka waqif perlu menegaskan tujuan wakafnya. Apakah harta yang diwakafkan itu untuk menolong keluarganya sendiri sebagai wakaf keluarga, atau untuk fakir miskin, dan lain-lain, atau untuk kepentingan umum yang jelas tujuannya untuk kebaikan.

d. Sighat (lafadz) atau pernyataan wakaf dapat dikemukakan dengan tulisan, lisan atau suatu isyarat yang dapat dipahami maksudnya. Pernyataan dengan tulisan atau lisan dapat digunakan untuk menyatakan wakaf oleh siapa saja, sedangkan cara isyarat hanya bagi orang yang tidak dapat menggunakan dengan cara tulisan atau lisan. Tentu pernyataan dengan isyarat tersebut harus sampai benar-benar dimengerti pihak penerima wakaf agar dapat menghindari persengketaan di kemudian hari. Secara garis besar, syarat sahnya shighat ijab, baik lisan maupun tuisan adalah:

1. Shighat harus munjaza (terjadi seketika/selesai). Maksudnya ialah sighat tersebut menunjukan terjadi dan terlaksananya wakaf seketika setelah sighat ijab diucapkan atau ditulis.

2. Sighat tidak diikuti syatar batil (palsu). Maksudnya ialah syarat yang menodai atau mencederai dasar wakaf atau meniadakan hukumnya, yakni kelaziman dan keabadiaan.

3. Sighat tidak diikuti pembatasan waktu tertentu dengan kata lain bahwa wakaf tersebut untuk selamanya. Wakaf adalah shadaqah yang disyarieeatkan untuk selamanya, jika dibatasi waktu berarti bertentangan dengan syariec at oleh karena itu hukumnya tidak sah. 
4. Tidak mengandung suatu pengertian untuk mencabut kembali wakaf yang sudah dilakukan.

Selain syarat dan rukun harus dipenuhi, dalam perwakafan sebagaimana disebutkan diatas, kehadiran nazir sebagai pihak yang diberi kepercayaan mengelola harta wakaf sangatlah penting. Walaupun para mujtahid tidak menjadikan nazir sebagai salah satu rukun wakaf, namun para ulama sepakat bahwa wakif harus menunjuk nazir wakaf, baik yang bersifat perseorangan maupun kelembagaan. Pengangkatan nazir wakaf ini bertujuan agar harta wakaf tetap terjaga dan terus, sehingga harta wakaf tidak sia-sia. Nazir sebagai pihak yang bertugas untuk memelihara dan mengurusi wakaf mempunyai kedudukan yang sangat penting dalam perwakafan. Sedemikian pentingnya kedudukan nazir dalam perwakafan, sehingga berfungsi tidaknya benda wakaf tergantung pada nazir itu sendiri. Untuk itu, sebagai instrumen penting dalam perwakafan, nazir harus memenuhi syarat-syarat yang memungkinkan, agar wakaf dapat memberdayakan sebagaimana mestinya.

Untuk lebih jelasnya persyaratan nazir itu dapat diungkapkan sebagi berikut:

1) Syarat moral

a. Paham tentang hukum wakaf dan ZIS, baik dalam tinjauan syariee ah maupun perundang-undangan RI

b. Jujur, amanah dan adil sehingga dapat dipercaya dalam proses pengelolaan dan tepat sasaran kepada tujuan wakaf

c. Tahan godaan terutama menyangkut perkembangan usaha

d. Memiliki kecerdasan, baik emosional maupun spiritual

2) Syarat manajemen

a. Mempunyai kapasitas dan kapabilitas yang baik dalam leadership

b. Visioner

c. Mempunyai kecerdasan yang baik secara intelektual, sosial dan pemberdayaan

3) Syarat bisnis

a. Mempunyai keinginan

b. Mempunyai pengalaman

c. Memiliki ketajaman melihat peluang usaha Dalam persyaratan yang telah dikemukakan di atas menunjukan bahwa nazir menempati pos yang sangat sentral dalam pola pengelolaan harta wakaf. Ditinjau dari segi tugas 
nazir, dimana dia berkewajiban untuk menjaga, mengembangkan dan melestarikan manfaat dari harta wakaf yang diwakafkan bagi orang-orang yang berhak menerimanya, jadi jelas berfungsi atau tidaknya wakaf bergantung pada peran nazir. ${ }^{8}$

${ }^{8}$ Astuti, Arso, dan Wigati, “済無No Title No Title No Title.” 


\section{BAB III PENUTUP}

A. Kesimpulan

Secara bahasa, wakaf berasal dari kata waqf yang berarti radiah (terkembalikan), al-tahbis (tertahan), al-tasbil (tertawan), dan al-man'u (mencegah). Secara istilah, para ulama mendefinisikan wakaf sebagai berikut:

1. Muhammad al-Syarbini al-Khatib berpendapat bahwa wakaf ialah penahanan harta yang memungkinkan untuk dimanfaatkan disertai dengan kekalnya zat benda dengan memutuskan (memotong) tasharruf (pertolongan) dalam penjagaannya atas mushrif (pengelola) yang dibolehkan adanya.

2. Ahmad Azhar Basyir berpendapat bahwa yang dimaksud dengan wakaf ialah menahan harta yang dapat diambil manfaatnya yang tidak musnah seketika, dan untuk penggunaan yang dibolehkan serta dimaksudkan untuk mendapat rida Allah.

3. Idris Ahmad berpendapat, wakaf ialah menahan harta yang mungkin dapat diambil manfaatnya, kekal zatnya, dan menyerahkannya ke tempat-tempat yang telah ditentukan syara' serta dilarang leluasa pada benda-benda yang dimanfaatkannya itu.

Adapun hukum wakaf dapat dilihat dari berbagai sumber yang mendasar, diantaranya adalah sebagai berikut.

1. Al Quran

2. As-Sunnah (hadits)

3. Perundang-Undangan

Adapun rukun dan syarat wakaf adalah sebagai berikut.

1. Wakif adalah orang yang mewakafkan

2. Mauquf adalah barang yang diwakafkan

3. Mauquf 'alaih adalah orang atau lembaga yang berhak menerima harta wakaf

4. Shigat adalah pertanyaan wakif sebagai suatu kehendak untuk mewakafkan harta bendanya.

B. Saran 
Wakaf adalah suatu zat atau harta kekal yang dikeluarkan berdasarkan syarat dan ketentuannya yang bertujuan untuk mendekatkan diri kepada Allah guna untuk mendapatkan pahala. Sebagai manusia, kita sebaiknya harus tolong menolong terutama dalam berbuat kebaikan, salah satu contohnya adalah wakaf. Wakaf akan menjadi amal jariyah buat kita untuk menjadi amal akhirat kita kedepannya. 


\section{DAFTAR PUSTAKA}

Astuti, Sinta Indi, Septo Pawelas Arso, dan Putri Asmita Wigati. “済無No Title No Title No Title." Analisis Standar Pelayanan Minimal Pada Instalasi Rawat Jalan di RSUD Kota Semarang 3 (2015): 103-11.

DETIK.COM. "Seputar Wakaf: Pengertian, Hukum, Rukun, dan Syaratnya." 3 FEBRUARY 2021, n.d. https://www.kai.or.id/berita/18587/seputar-wakafpengertian-hukum-rukun-dan-syaratnya.html.

Rahman, Muhammad Fudhail. "Wakaf Dalam Islam.” Al-Iqtishad: Jurnal Ilmu Ekonomi Syariah 1, no. 1 (2009). https://doi.org/10.15408/aiq.v1i1.2455.

Rosadi, H. Aden. Zakat dan Wakaf Konsepsi, Regulasi, dan Implementasi. Vol. 53, 2019.

SCRIBD, Bagas. "Rukun Dan Syarat Wakaf.” 23 september 2016, n.d. https://id.scribd.com/document/325004111/Rukun-Dan-Syarat-Wakaf.

رازى ,محمد ابن زكرياى. "Buku Pintar Wakaf,” 1384. 